\title{
Further Development of the Sextupole and Decapole Spool Corrector Magnets for the LHC
}

\author{
M. Allitt, A. Ijspeert, M. Karppinen, J, Mazet, J. Porez, J. Salminen \\ CERN, LHC Division, Geneva, Switzerland \\ S. Bapna, M. Karmarkar, A. Puntambekar, K, Ruwali, A. Thipsay \\ CAT, Indorc, India
}

\begin{abstract}
In the Large Hadron Collider (LHC) the main dipoles will be equipped with sextupole (MCS) and decapole (MCD) spool correctors to meet the very ligh demands of field quality required for the satisfactory operation of the machine. Each decapole corrector will in addition have an octupole insert (MCO) and the assembly of the two is designated MCDO. These correctors are needed in relatively large quantities, i.e. 2464 MCS Sextupoles and 1232 MCDO Decapole-Octupole assemblies. Half the number of the required spool correctors will be made in India through a collaborntion between CERN and CAT (Centre for Advanced T'eclinology, Indore, India), the other half will be built by European industry. The paper describes final choices concerning design, materials, production techniques, and testing so as to assure economic magnet manufacture but while maintaining a homogenous magnetic quality that results in a robust product.
\end{abstract}

\section{INTRODUCTION}

T'he main dipoles of LHC will be equipped with Sextupole (MCS) and Decapole (MCD) "spool" correctors. Each decapole corrector will in addition have an Octupole insert (MCO) atd these together are designated as MCDO. In total $2464 \mathrm{MCS}$ and $1232 \mathrm{MCDO}$ assemblies are required for the LHC. Half of these will be made in India in a collaboration between CERN and CAT (Contre for Advanced Technology, Indore), the remainder will be built by European industry. A number of prototypes of both MCS and MCD have been built and tested to confirm the design and to refine the construction techniques, and results have been reported in MT-15. This paper focuses on further development that has been undertaken in relation to choice of materials, assembly techniques and test requirements for the series production of the LHC spool correctors.

\section{DESCRIITION}

The heart of the MCS and MCD spool correctors for which the main parameters are given in Table 1 , consists of a cylindrical coil assembly. This is surrounded by a glass fiber insulation layer and centered inside steel laminations. Radial pressure is obtaitned from an aluminum cylinder shrink-liuted

Manuscript received 26 Septenther 1999.
TABLE-I

Main Parameters of Srool Corrfctors

\begin{tabular}{|c|c|c|c|}
\hline Parameters & MCS & $\mathrm{MCD}$ & \\
\hline Nominal strength & $1630 \mathrm{~T} / \mathrm{m}^{2}$ & $1,2 \times 10^{6}$ & $T / m^{4}$ \\
\hline Magnetic length & 111 & 66 & $\mathrm{~mm}$ \\
\hline Overall lengih with shiokl & 160 & 110 & $\mathrm{~mm}$ \\
\hline Aperture & 58 & 63.6 & min \\
\hline I.D. and O.D. shrinking cyl. & $95 / 101,4$ & $89.9 / 96$ & min \\
\hline Nominal current & 550 & $\$ 50$ & A \\
\hline Working/Tost teinp. & $1.9 / 4.2$ & $1.9 / 4.2$ & $\mathbf{K}$ \\
\hline Tums per coil/ no. of coils & $2 \times 13 / 6$ & $2 \times 20 / 5$ & \\
\hline Solf inductance & 0.8 & 0.4 & $\mathrm{mH}$ \\
\hline Critical current at $1.9 \mathrm{~K} / 4.2 \mathrm{~K}$ & $1300 / 950$ & $1250 / 915$ & A \\
\hline Peak freid in coil in $3 \mathrm{D}$ & 1.9 & 2.4 & $\Gamma$ \\
\hline Mass. & -5.5 & $-4,0$ & $\mathrm{Kg}$ \\
\hline
\end{tabular}

around the laminations. The assembly is completed with end plates for coil connections and a parallel resistor for magnet protection. The magnet is housed in a magnetic shield also acting as a support $[1,2]$.

The sextupole MCS has six coils whereas the decapole MCD has five [3], Each of these coils consist of a double pancake wound from a monolithic rectangular superconducting wire, PVA (poly-vinyl-acetate) enameled (parameters in Table II). The coils are wound by "counter winding" [4] on a specially contoured central island and held rigidly with end-spacers. Central islands and end spacers are made of G11 grade fiberglass epoxy which matches the thermal contraction of the coil. The coils in ench corrector are connected in series by ultrasonic welding, achieving contact resistances of less than then $5 \mathrm{n} \Omega$ /connection at liquid helium (LHe) temperature.

Pre-compression is applied to the coils by shrink fitting the aluminum cylinder (aluminium grade AA 5086) over the eccentric steel laminations which are stacked over the coils

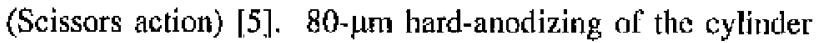
prevents corrosion between the cylinder and the steel laminations. A radial interference of $0.07 \mathrm{~mm}$ yieIds an azimuthal pre-compression in the coils of $20-50 \mathrm{MPa}$ at room tomperature and $30-60 \mathrm{MPa}$ at cold.

The spool correctors are mounted at the ends of the main dipole close to $12 \mathrm{kA}$ busbars. To prevent these from saturating the yoke of the correctors the latter are encapsulated in an iron-shiclding cylinder with coercivity $<120 \mathrm{~A} / \mathrm{m}$. The mounting flange of this shield contains precision dowel holes for alignment to the main dipole. A 30 - 4 m protective coating of nickel is applied for corrosion protection of the shicld. 
TABLE-II

WIRS PARAMETERS rOR MCS ANI MCD

\begin{tabular}{|c|c|c|}
\hline Parameters & Values & \\
\hline Material & NbTì in Cu matrix & \\
\hline Dimensions insulated wice & $1.25 \times 0.73 \pm 0.01$ & $\mathrm{~m}$ \\
\hline Insulation & $P V A$ & \\
\hline Insulation thickness & $0.06 \pm 0.01$ & $\mathrm{~mm}$ \\
\hline Filanent Twist pitch & $18 \pm 2$ & mint \\
\hline Cu/Sc tatio & $1.6 \pm 0.1$ & \\
\hline RRR of Cu matrix & $>100$ & \\
\hline $\begin{array}{l}\text { Critical current ( } 5 \mathrm{~T}, 4,2 \mathrm{~K} \text { ) } \\
\text { (perpendicular / parallel to broad sicte) }\end{array}$ & $>630 / 700$ & $A$ \\
\hline
\end{tabular}

In the LHC the MCS spool correctors will be powered in families ol 154 connected in series. If one magnet quenches the energy of the whole family ( $\sim 25 \mathrm{~kJ})$ will be dissipated in that corrector. Theretore each MCS cortector thas been protceted with a 0.1 Ohm shunt resistor made of of $5 \mathrm{~mm}$ stainless sted wire, wound non-inductively around the magnet in the cylindrical space botween magnet and shicld.

\section{Producrion TECINIQULS}

Because of the tight tolcrances, the fabrication of the intricately shaped contral islands and end spacers from glassCiber epoxy material, and the winding of the coils and their assembly, are demanding operations [6].

\section{A. Coil Winding Machines.}

After the initial development of a twin-arm manual coil winding fixture, more advanced automatic coil winding machines were developed hased on different principles, one at Ferrara Univ., Italy, through Instituto Nazionale di Fisica Nucleare (INFN) and another at CAT through Patel's Analog and Digital Measurement Co Ltd. (PADMC), Pune, India. MCS and MCD coils have been successfully wound an these machines. The Fertara machine is an elaborate

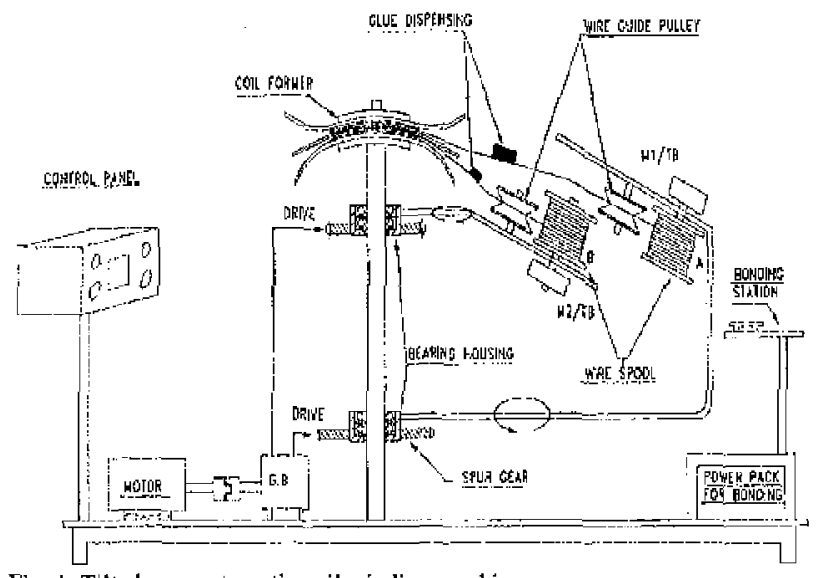

Fig. 1. Tilted-arm aulomatic coil winding machine. intelligent robot with a rocking coil mandrel. It is capable of winding coils of different widths and lengths. The CAT machine (Fig.1) is rather simple and suited for small MCS and MCD coils. It employs mechanical cams and tilted rotating arms. The coil mandrel is of the non-rocking type. CAT also designed a second type, a simple notorized version of the earlier twin-arm mantal winding fixturo. For series production anyone of these could be used.

\section{B. Central Islands and End Spacers.}

These complex shapes are produced from glass-fiber epoxy (Fig.2), an unfriendly material for machining. Molding appeared to be the lirst choice for a large series. Prototypes wero made both by Rosin Transfer molding and Compression molding, using an adapted curing process and a special CNC (Computer Numerical Control) machined mould. However given the large number of pieces to be produced the risk of inconsistent quality dne to variation in the distribution of resin and fibers is notn-negligible and therefore fabrication of these pieces by CNC milling from a standard G11 glass-fiber tube is preferred. In this case, care has to be taken to use tube which is stress-rolieved by pre-slitting, and also the wear of the cutting tool must be considered when machining bulk quantitics.

\section{Coil Curing.}

The coils are wet wound using epoxy AW 106 resin \& HV $953 \mathrm{U}$ hardener in ratio of $10: 8 \mathrm{pbw}$ (part by weight) of CIBA Chemicals and cured either by oven heating of the coil in its mould or by resistive heating of the coil passing a cutrent through its wire. Coating the inside of the mould with a thermal insulation material like Teflon ${ }^{\text {in }}$ avojols heat transfor from the coil to the tooling and also helps in releasing the coil from the mould after curing.

\section{Insulation Around the Coil Assembly.}

A slotted glass-fiber tube charged with epoxy glue is slipped and glued over the coil assenbly. The slot is carcfully measured and filled with G-11 shims to avoid locally a resin rich area. This method has successfully replaced the earlicr method of wrapping a $B$-stage glass cloth around the coil, the curing of which was a rather lengthy process. After curing, the insulating slit tube is machined to a preciso outside diameter to obtain the correct interference (Fig.3).

\section{E. Coil Teminal Joining.}

First generation prototypes employed soldered connections using standard tin-lead. solder with long connections to keep the contact resistance as low as possible. A more clegant Ultrasonic Welding (USW) has been adopted for terminal joining. With this a joint resistance as low as $5 \mathrm{n} \Omega$ per connection has been achieved. 


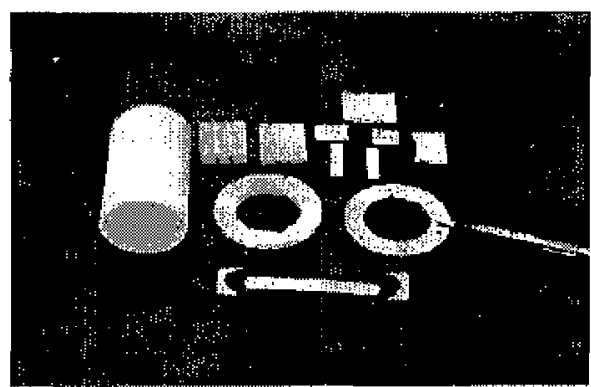

Fïg. 2. G-11 glass-fiber components

\section{F. Steel Laminations.}

Laminations of $1 \mathrm{~mm}$ thick low carbon stecl (Fe 99.99\%) and $0.5 \mathrm{~mm}$ thick cold-rolled silicon steel (type AISI M 45) have successfully been used in prototypes. For series production $1.5 \mathrm{~mm}$ thick low carbon sted has been selected as it is of relatively low cost and reduces the number of laminations required. The laminations are produced by the fine blanking technique which ensures the close dimensional aceuracy required to guarantee correct pre stress, and also enables straightforward production of $0.03 \mathrm{~mm}$ nipples to facilitale sliding of laminations over each other as the shrinking cylinder contracts. The low carbon steel laminations necd a surface treatment for corrosion protection.

\section{G. Shrink-Fitting of Aluminium Cylinder.}

Experience has shown that a custom made clectric band heater around the cylinder is sufficient to heat the cylinder. A conieal tool of Teflon placed on top of the stack of laminations helps align the shrinking cylinder. A simple steel cylinder, with the same inner diameter as the heated aluminum cylinder, is first slipped over the stack of laminations to check their alignment.

\section{H. Alignment Dowels.}

The speol corrector needs to be aligned very precisely $(+/ .0 .1 \mathrm{~mm})$ with respect to the axis of the main dipole magnet. Two alternative methods bave been used. In the first method the magnetic axis of the corrector magnet is determined by measurement on the magnetic measurement bench at room temperature [7] and the dowel holes are then drilled according to measurement. In the second method all the components are produced with dowel holes of sufficient precision $(0,04 \mathrm{~mm})$ and the measurement on the magnetic bench is used to verify the accuracy. The sccond method has been adopted as the preferted method.

\section{QuALITY CIIBCKS}

To ensure reliable and lail safe operation of the spool correctors rigorous quality checks are necessary at every stage. Mechanical measurement of each of the eritical components like central islands, end-spacers, coils, shrinking cylinders and dowels in the steel screen as well as electrical

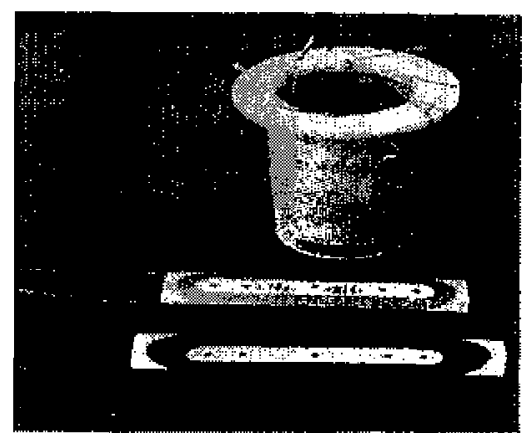

Tig. 3. Assembled coils and coil terminations

checks on each coil and assembly of coils are required. In addition all tooling, fixtures and process parameters like coil curing cycle time and temperature and contact welding parameters are checked and cortified before use in production. The acceptance limits are found in the technical specilications of the MCS and MCD $[1,2]$.

\section{A. Training at $4.2 k$.}

In addition all spool correctors will be cold tested by the manufactuser at $4.2 \mathrm{~K}$ in liquid helium and trained up to the critical current. Special cryostats, power-converter $3 \mathrm{~V}$, $1500 \mathrm{~A}$ ) and $\mathrm{PC}$ based quench data acquisition system have been designed for testing of the series production (Fig.4). During this test the resistance of the joints of each corrector is moasured at $600 \mathrm{~A}$ at $4.2 \mathrm{~K}$. Tho allowable limit is $27 \mathrm{n} \Omega$ for the total resistance of a correclor magnet.

\section{B. Magnetic Measurements at Room Temperature.}

The magnetic field quality as well as the precision of alignment (dowel-pin holes) is measured at room temperature on a dedicated tost bench using a rotating search coil, powering the correctors with $1-2 \mathrm{~A}$ current. Table-III shows typical acceptance critcria for the MCS.

\section{Estimated Production Timps and COST}

$\Lambda$ production rate of about 50 MCS magnets and 25 MCDO magncts per month is required to match the production of the main dipoles of LHC. The typical fabrication eycle consists of 8 hours for winding, curing and assembly of the coils, 3 hours for the assembly of laminations, shrinking cylinder, iron screen including mechanical and electrical checks, 1 hour for the magnetic measurements at room temperature, 8 hours for training at

Table III

Typtcal Magnetic Field Acceptanci CRiteria for tili MCS

\begin{tabular}{ll}
\hline Parameter & \multicolumn{1}{c}{ Acceptance Criteria } \\
\hline Normal/skew Quad. & For Alignment Precision \\
& $<1 \%$ of sext, field at $\mathrm{R}=17 \mathrm{~mm}$ \\
& $(=$ axis shift of $0.1 \mathrm{~mm})$ \\
Skew Sextupole & $<0.5 \%$ of normal sextupole \\
& $(=$ twist angle of 1.5 mirad $)$ \\
& For Quality Control \\
Sextupole strength & Within $1 \%$ of theor. strength \\
Any other multipole & $<1 \%$ of sext. field at R=17 $\mathrm{mm}$ \\
\hline
\end{tabular}


$4.2 \mathrm{~K}$. With three coil winding and assembly stations, one magnetic measurement bench and two eryostats (cach holding three to five MCS or MCDO at a time) it is expected to achieve the required production rate safely. An estimate of the cost break-down of manufacture and testing of the MCS based on the prototype work is givon in Table IV. The development of the coil winding machines, tooling, fixturcs and construetion techniques has been done at CERN and CAT while making prototypes and the know-how for intial production and training is provided to the European and Indian manulacturers. In addition the test bench for warm magnetic measurements and the quench detection system is provided to the manufacturers.

\section{VI, Conclusions}

Further development of the spool correctors has led to final choices of materials and processes assuring economic and robust magncts. The options have been successfully tested on prototypes and with this experience we are now starting up the series production with confidence. CERN has awarded the contract for the series production and testing of 1232 MCS to European industry. The training tost and magnetic ficld measurement will be done at the factory. CAT has also placed an order with an Indian industry for manufactute of $1300 \mathrm{MCS}$. The tosting at $4.2 \mathrm{~K}$ of the latter series will be done in-house at CAT for which all necessary cryostats, powering and data acquisitions system etc. have been ordered.

\section{ACKNOWLEDGMENTS}

We wish to acknowledge the support provided by L. Walckiers, G. Laurent and H. Durand (CERN), K.G. Vaishnav and R. Adbol (CAT) and the encouragement of N. Siegel and T. Taylor (CERN) and D. Bawalkhar (CAT)

TABIE IV

Estimated breate-Down of Manglacturimit Cost.

\begin{tabular}{lc}
\hline Work Package & Percent of Total Cost \\
\hline & \\
Designdocumentation & $5 \%$ \\
Machines, tooling & $10 \%$ \\
Component fabrication & $25 \%$ \\
Coil winding, magnet assembly & $25 \%$ \\
Inspection, Testing (R.T,and cold) & $35 \%$ \\
\hline
\end{tabular}

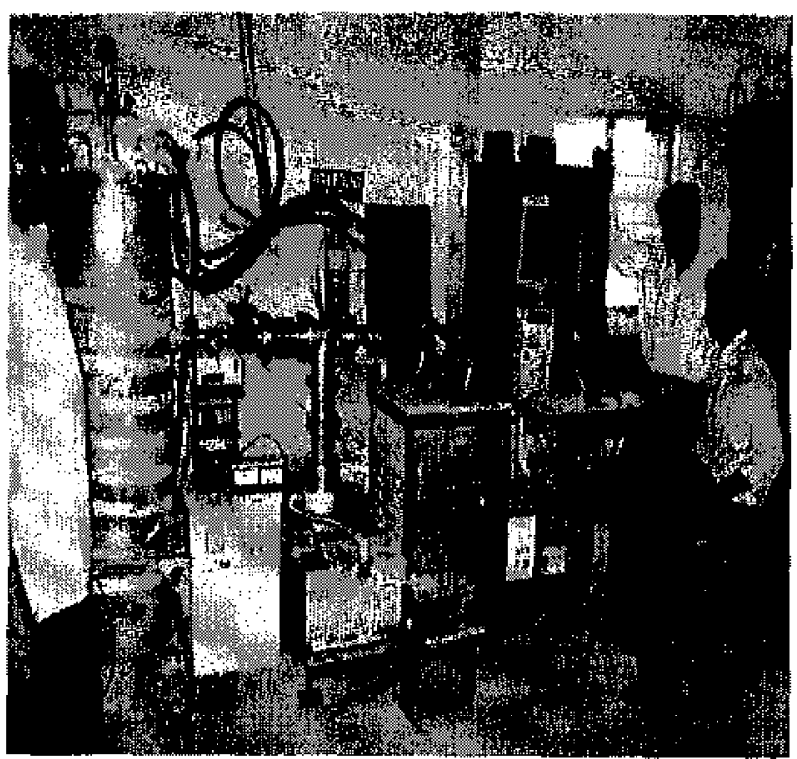

Fig. 4. Cold test set up in Indore.

\section{REITRENCF:}

[1] "Technical spepification for the supply of sextupole spool corrector magnets MCs for the LHC superconducting dipole magnets", LHCMC-Cl-0001, Feb'99

[2] "Technical specification for the supply of decapole and octupole spool corrector magnets MCOO for the LHC superconducting dipole magnets", L-HC-MCDO-CI-0001, Jume "99

[3] J. Salminen, A. Ijspeer, "Experience with different constructions of saperconducting corrector magnets for the LHC', EPAC98,Stookhoim, Sweden, June 1998.

[4] J. Salminen, A. Ijspeert, A. Puntambekac, "Super condueting sextupole corretor magnet for the LHC main dipoles", ElMA-96, Sitiges, Spain, June 1996

[5] A. ljspeert, J. Salminen, "Superconducting coil compression by scissor laminations", EPAC-96, Sitges, Spain, June 1996.

(6) J. Salminen et al, "Experience with the fabrication and testing of the sextupole supercondueting eorretor magnets for the LHC', MT-15, Reijing, Oct1997.

[7] Z. Ang et al., "Measurements of the I.HC corrector magnets at room and cryogenic temperatures", EPAC-98, Stockholm, Sweden, Jnne 1998. 